\title{
Thermal Distribution of Ultrasound Waves in Prostate Tumor: Comparison of Computational Modeling with In Vivo Experiments
}

\author{
Forough Jafarian Dehkordi, Ali Shakeri-Zadeh, Samideh Khoei, \\ Hossein Ghadiri, and Mohammad-Bagher Shiran \\ Department of Medical Physics, Faculty of Medicine, Iran University of Medical Sciences (IUMS), 14155-5983 Tehran, Iran \\ Correspondence should be addressed to Mohammad-Bagher Shiran; mshiran@tums.ac.ir
}

Received 23 June 2013; Accepted 5 August 2013

Academic Editors: J. H. Wu and G. Zheng

Copyright (C) 2013 Forough Jafarian Dehkordi et al. This is an open access article distributed under the Creative Commons Attribution License, which permits unrestricted use, distribution, and reproduction in any medium, provided the original work is properly cited.

\begin{abstract}
Ultrasound irradiation to a certain site of the body affects the efficacy of drug delivery through changes in the permeability of cell membrane. Temperature increase in irradiated area may be affected by frequency, intensity, period of ultrasound, and blood perfusion. The aim of present study is to use computer simulation and offer an appropriate model for thermal distribution profile in prostate tumor. Moreover, computer model was validated by in vivo experiments. Method. Computer simulation was performed with COMSOL software. Experiments were carried out on prostate tumor induced in nude mice (DU145 cell line originated from human prostate cancer) at frequency of $3 \mathrm{MHz}$ and intensities of $0.3,0.5$, and $1 \mathrm{w} / \mathrm{cm}^{2}$ for 300 seconds. Results. Computer simulations showed a temperature rise of the tumor for the applied intensities of $0.3,0.5$ and $1 \mathrm{w} / \mathrm{cm}^{2}$ of $0.8,0.9$, and $1.1^{\circ} \mathrm{C}$, respectively. The experimental data carried out at the same frequency demonstrated that temperature increase was $0.5,0.9$, and $1.4^{\circ} \mathrm{C}$ for the above intensities. It was noticed that temperature rise was very sharp for the first few seconds of ultrasound irradiation and then increased moderately. Conclusion. Obtained data holds great promise to develop a model which is able to predict temperature distribution profile in vivo condition.
\end{abstract}

\section{Introduction}

Prostate cancer is one of the most common malignant cancers in men [1]. There are a variety of treatments for prostate cancer among which chemotherapy is one of the most important methods. Application of chemotherapy for treatment of cancer is associated with some limitations. Today, drug targeting towards cancer cells and increasing drug concentration inside the tumor are the greatest purposes of researchers because systematic distribution of the anticancer agent may induce damages in normal tissue $[2,3]$. Application of ultrasound is one of the basic techniques which has been used to increase the efficiency of drug delivery [4].

Traditionally, ultrasound waves have been used either for ultrasound hyperthermia or physiotherapy to warm the tissue or to kill cancerous cells [5]. Due to the ability of deep penetration into the living tissues, application of ultrasound wave has recently become an interesting area in noninvasive treatment and diagnostic medicine [6]. Ultrasound wave can deliver mechanical energy into the desired area inside the body. Absorption of ultrasound mechanical energy can increase tissue temperature to a relatively high value which may be used in therapy [7]. In drug delivery, ultrasound waves vibrate drug carriers and cell membrane to increase the amount of drug received by desired cells [8]. This mechanism depends on the produced heat by ultrasound waves which is controlled by the intensity and frequency of the waves [8]. Therefore, determination of temperature variation as a result of ultrasound irradiation to tissue is important in drug delivery.

In order to get precise prediction of response of exposed tissue to the ultrasound wave, it is important to determine thermal distribution of absorbed ultrasound wave in the region of interest [6]. Thermal distribution inside tissue 
has been modeled by many researchers [9-11]. The heat transfer in soft tissue can be described using Pennes' bioheat equation, which is based on the classical Fourier law of heat conduction and introduced by Pennes in 1948 [12]. This model is used to address the heat transfer in living tissues. Pennes' equation is based on the assumption of the energy exchange between the blood vessels and the surrounding tissues [13]. Pennes' model may provide suitable temperature distributions in whole body, organ, and tumor analysis under study [14]. Moreover, recent calculations of the comparative study of ultrasound waves represent the maximum temperature elevation of $0.4^{\circ} \mathrm{C}$ in embryonic model tissues for the exposure of $1 \mathrm{~min}$ [15]. Also the use of COMSOL software to model ultrasound hyperthermia of breast tumor has been evaluated by Hassan et al. in 2009 [5]. COMSOL is a powerful interactive environment for modeling and solving all kinds of scientific and engineering problems, and through such a useful software thermal distribution can be simulated based on Pennes' equation [16]. The aim of present study was to determine temperature variation due to ultrasound wave irradiation to prostate tumor by computer modeling and in vivo experiments.

\section{Materials and Methods}

2.1. Simulation. Effects of ultrasound on tissue heating were modeled in two phases. At first, the acoustic pressure of sound in tissue was solved using wave equations. Secondly, the diffusion of heat in the tissue was calculated using the obtained acoustic pressure as the source term. In order to calculate pressure field generated by the acoustic source in attenuation media, Helmholtz equation was used:

$$
\nabla \cdot\left(\frac{1}{\rho} \nabla P\right)+\frac{\omega^{2}}{\rho c} P=0 .
$$

Here, $\rho\left(\mathrm{kg} / \mathrm{m}^{3}\right)$ refers to the density, $c(\mathrm{~m} / \mathrm{s})$ denotes the speed of sound, and $\omega=2 \pi f(\mathrm{rad} / \mathrm{s})$ is the angular frequency, with $f(\mathrm{~Hz})$ explaining the frequency. Based on bioheat equation, experimental condition was simulated in COMSOL Multiphysics (Royal Institute of Technology in Stockholm, Sweden) software. At first, it is necessary to define appropriate geometry for the software. Geometry of the experimental study including piezoelectric, tumor, and surrounding (soft) tissues was defined and modeled in the software in 2D dimensions. All acoustic characteristics given in Table 1 were replaced in the Pennes equation as follows:

$$
\rho_{t} c_{t} \frac{\partial T_{t}}{\partial t}=k_{t} \nabla^{2} T_{t}-\rho_{b} \omega_{b} c_{b}\left(T_{t}-T_{b}\right)+Q_{m}+Q_{\mathrm{ext}},
$$

where $\rho$ is the tissue density $\left(\mathrm{kg} \mathrm{m}^{-3}\right), c$ is the specific heat of tissue $\left(\mathrm{J} \mathrm{kg}^{-1} \mathrm{~K}^{-1}\right), k$ is the tissue thermal conductivity $\left(\mathrm{W} \mathrm{m}{ }^{-1} \mathrm{~K}^{-1}\right)$, and $\rho_{b} c_{b} \omega_{b}\left(T_{t}-T_{b}\right)$ is a source term accounting for blood perfusion. $\rho_{b}$ is the density of blood, $c_{b}$ is the specific heat of blood, $\omega_{b}$ is the blood perfusion rate $\left(\mathrm{s}^{-1}\right)$, and $T_{t}$ is the arterial blood temperature (assumed to equal $37^{\circ} \mathrm{C}$ ). $Q_{m}$ (the heat source from metabolism $\left.\left(\mathrm{w} \mathrm{m}^{-3}\right)\right)$ is neglected since it is small. $Q_{\text {ext }}$ is the heat source term that is computed by taking
TABLE 1: Thermal properties of tumor and blood used in numerical calculation $[1,2,18,19]$.

\begin{tabular}{lcccc}
\hline Tissue & $\rho\left(\mathrm{kg} \mathrm{m}^{-3}\right)$ & $\begin{array}{c}\mathrm{C} \\
\left(\mathrm{j} \mathrm{kg}^{-1} \mathrm{~K}^{-1}\right)\end{array}$ & $\begin{array}{c}K \\
\left(\mathrm{w} \mathrm{m}^{-1} \mathrm{~K}^{-1}\right)\end{array}$ & $\begin{array}{c}C \\
\left(\mathrm{~m} \mathrm{~s}^{-1}\right)\end{array}$ \\
\hline Prostate tumor & 1086 & 3310 & 0.45 & 1660 \\
Blood & 1058 & 3850 & 0.47 & - \\
\hline
\end{tabular}

into account the local pressure $p$, absorption $\alpha$, density $\rho$, and sound velocity $c$ as follows [17]:

$$
Q_{\text {ext }}=\frac{2 \alpha|P|^{2}}{\rho c} \text {. }
$$

The simulation was performed by COMSOL software at three different intensities of $0.3,0.5$, and $1 \mathrm{w} / \mathrm{cm}^{2}$ and the frequency of $3 \mathrm{MHz}$. The initial temperature of the tumor was set at $37^{\circ} \mathrm{C}$ for all performed simulations and run time (ultrasound exposure) was set at 300 seconds.

2.2. In Vivo Experiments. Human prostate cancer cells (DU145 cell line) were obtained from Pasteur Institute of Iran. Cells were grown in RPMI 1640 medium with $10 \%$ fetal calf serum, $100 \mathrm{units} / \mathrm{mL}$ penicillin, and $100 \mu \mathrm{g} / \mathrm{mL}$ streptomycin at $37^{\circ} \mathrm{C}$ in $5 \% \mathrm{CO}_{2}$. Cells were harvested by trypsinizing cultures with $1 \mathrm{mM}$ EDTA/0.25\% Trypsin (w/v) in phosphate buffer saline (PBS). When DU145 cells reached $40 \times 10^{6}$ in number, 4 male nude mice were implanted in the right flank subcutaneously with $10 \times 10^{6}$ of cells in $100 \mu \mathrm{L}$ RPMI 1640 , and when tumors reached appropriated volume of $100 \mathrm{~mm}^{3}$, in vivo experiments were carefully conducted. All animal procedures were conducted in accordance with institutional Animal Care Committee guidelines. For ultrasound exposure, a mouse was anesthetized with an intramuscular injection of $100 \mathrm{mg} / \mathrm{kg}$ ketamine and $20 \mathrm{mg} / \mathrm{kg}$ xylazine. The mouse was then mounted face down on a custom-made Perspex holder, and the tumor was covered with ultrasound coupling gel. In order to measure temperature variation, a thermocouple probe with diameter of $125 \mu \mathrm{m}$ with sensitivity of $0.1^{\circ} \mathrm{C}$ (Hanyoung, Korea) was inserted inside the tumor. The tumor exposed to ultrasound in last axial maximum of a circular piston transducer operating at $3 \mathrm{MHz}$ in the continuous wave mode. Sonication carried out for period of $300 \mathrm{sec}$ at intensities of $0.3,0.5$, and $1 \mathrm{w} / \mathrm{cm}^{2}$. The temperature was monitored and recorded at one-minute interval.

\section{Results and Discussion}

Due to the capability of deep penetration and transferring energy, ultrasound waves are being used in medicine for treatment and diagnosis purposes. In drug delivery, as a main application of therapeutic ultrasound, mechanism of drug releasing in intracellular environment and tissue's drug uptake may be affected by ultrasound intensity and frequency. Present study which was performed in two phases revealed that ultrasound pressure distribution and thermal distribution are inhomogeneous. 


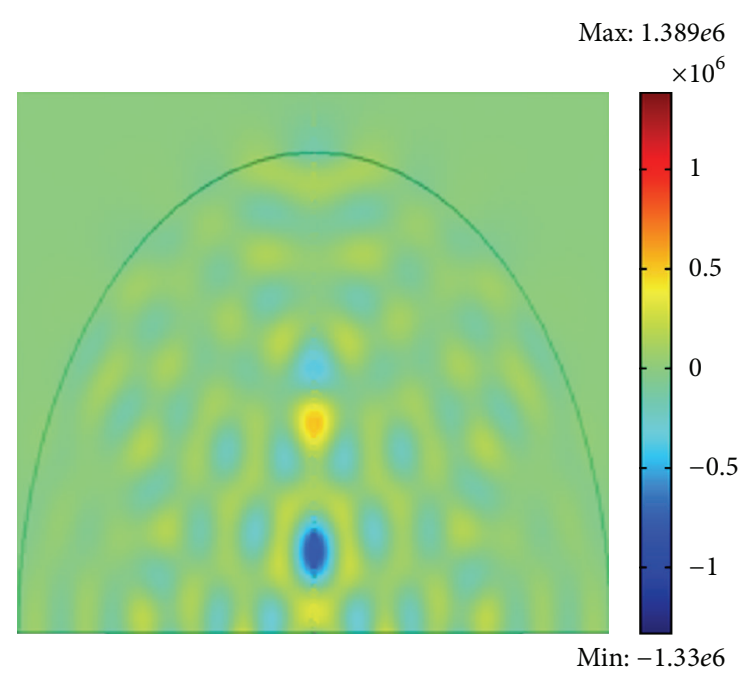

FIGURE 1: Computer simulation of acoustic pressure map in tumor.

Figure 1 illustrates inhomogeneous acoustic pressure distribution generated by $3 \mathrm{MHz}$ transducer in tumor. This finding is in good agreement with physics of ultrasound irradiation indicating that interferences of ultrasound wave fronts produce inhomogeneous pattern of pressure distribution [20,21]. Temperature-time curves obtained from our simulations and in vivo experiments are shown in Figures 2,3 , and 4 . Both simulation and experiment demonstrated that elevation of temperature depends on intensity. Moreover, based on the temperature-time curves of all experiments, the rate of temperature rise was very sharp at the first few seconds of sonication and then reached equilibrium which shows good correlation with computer simulation. Curiel et al. [22] have reported an experimental evaluation of lesion prediction modelling in the presence of ultrasound waves. Their modelling was performed utilizing the bioheat transfer equation and used to predict the lesions produced by a truncated spherical transducer designed for prostate. They sonicated the tissue with intensity of $2.33 \mathrm{w} / \mathrm{cm}^{2}$ for short periods and observed temperature rises steeply during the first few seconds of sonication. In another study done by Souchon et al. [23], the temperature elevation inside a liver sample during sonication (at high intensities and short exposure times) was simulated using the bioheat transfer equation. They also demonstrated that a steep temperature gradient may be predicted at the first seconds of sonication and that there is good correspondence between simulation and their examination.

As mentioned above, ultrasound may be effective in targeted chemotherapy by increasing drug uptake level of the tumor through macroscopic mechanisms of macromolecular massage of the cell membrane [24]. In respect to macromolecular massage of the cell membrane, when we intend to take advantage of nonthermal effects of ultrasound, it will be very important to apply energies not inducing destructive thermal distributions. Taken together, we proved that ultrasound intensities less than $1 \mathrm{w} / \mathrm{cm}^{2}$ at frequency of $3 \mathrm{MHz}$ are suitable to be used (for a period of $300 \mathrm{sec}$ ) if one

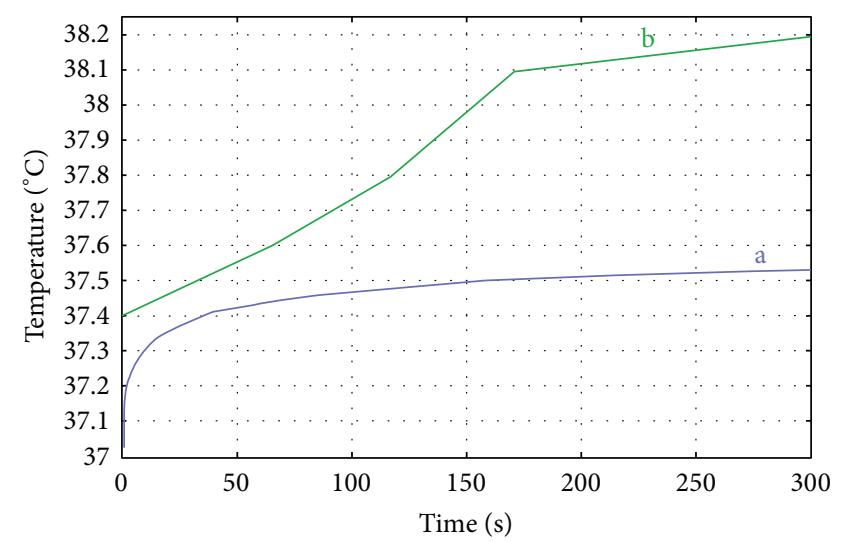

FIGURE 2: Temperature-time curve of ultrasound wave at frequency of $3 \mathrm{MHz}$, intensity of $0.3 \mathrm{w} / \mathrm{cm}^{2}$, and at run time 300 seconds (a) in simulation and (b) in in vivo experiment.

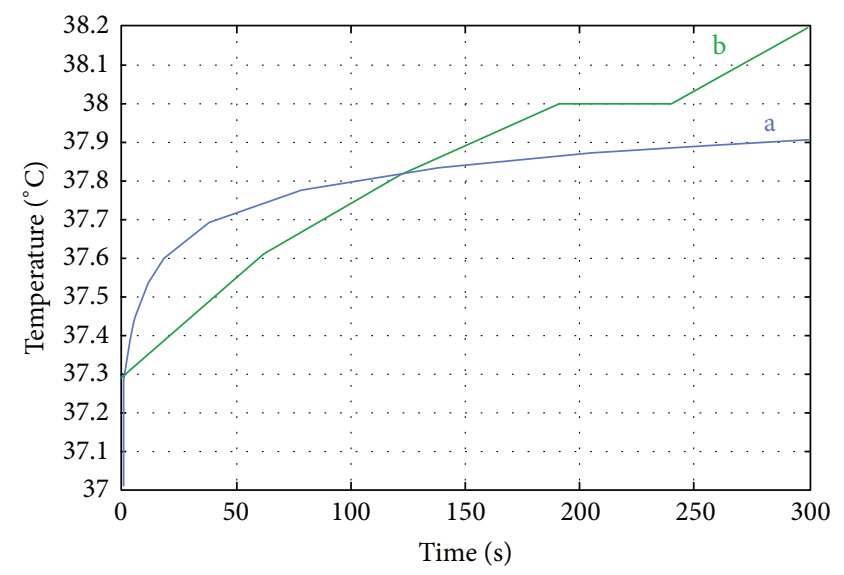

FIGURE 3: Temperature-time curve of ultrasound wave at frequency of $3 \mathrm{MHz}$, intensity of $0.5 \mathrm{w} / \mathrm{cm}^{2}$, and at run time 300 seconds (a) in simulation and (b) in in vivo experiment.

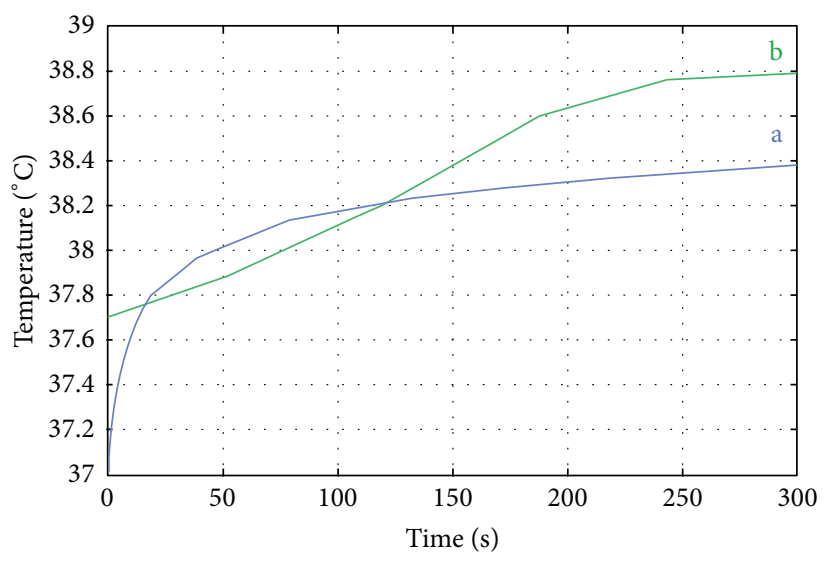

FIGURE 4: Temperature-time curve of ultrasound wave at frequency of $3 \mathrm{MHz}$, intensity of $1 \mathrm{w} / \mathrm{cm}^{2}$, and at run time 300 seconds (a) in simulation and (b) in in vivo experiment. 
would like to take advantage of macromolecular effects of ultrasound in chemotherapy and enhancing the level of taken drug by cells.

\section{Conclusion}

We present computer simulations to predict the amount of temperature elevation during ultrasound exposure of prostate tumor at different intensities. Our model suggests a direct correlation between temperature elevation and intensity of ultrasound for the same period of sonication. The rate of temperature rise was directly proportional to ultrasound intensity. Modeling results agree with preliminary in vivo results in xenograft nude mice model with regard to temperature elevation. In conclusion, data obtained in both computational and experimental studies holds great promise to develop a model which is able to predict temperature distribution profile with in vivo condition.

\section{Conflict of Interests}

The authors declare that there is no conflict of interests.

\section{References}

[1] A. Blana, B. Walter, S. Rogenhofer, and W. F. Wieland, "Highintensity focused ultrasound for the treatment of localized prostate cancer: 5-year experience," Urology, vol. 63, no. 2, pp. 297-300, 2003.

[2] M. A. Moses, H. Brem, and R. Langer, "Advancing the field of drug delivery: taking aim at cancer," Cancer Cell, vol. 4, no. 5, pp. 337-341, 2003.

[3] Z. Liu, K. Chen, C. Davis et al., "Drug delivery with carbon nanotubes for in vivo cancer treatment," Cancer Research, vol. 68, no. 16, pp. 6652-6660, 2008.

[4] I. V. Larina, B. M. Evers, T. V. Ashitkov, C. Bartels, K. V. Larin, and R. O. Esenaliev, "Enhancement of drug delivery in tumors by using interaction of nanoparticles with ultrasound radiation," Technology in Cancer Research and Treatment, vol. 4, no. 2, pp. 217-226, 2005.

[5] O. M. Hassan, N. S. D. Hassan, and Y. M. Kadah, "Modeling of ultrasound hyperthermia treatment of breast tumors," in Proceedings of the 26th National Radio Science Conference (NRSC '09), March 2009.

[6] K. P. Curra, P. D. Mourad, V. A. Khokhlova, R. O. Cleveland, and L. A. Crum, "Numerical simulations of heating patterns and tissue temperature response due to high-intensity focused ultrasound," IEEE Transactions on Ultrasonics, Ferroelectrics, and Frequency Control, vol. 47, no. 4, pp. 1077-1089, 2000.

[7] W. G. Pitt, G. Husseini, and B. J. Staples, "Ultrasonic drug delivery: a general review," Expert Opinion on Drug Delivery, vol. 1, no. 1, pp. 37-56, 2004.

[8] S. Humbert, T. Bettinger, F. Yan, and R. H. Guy, "Plasma membrane poration induced by ultrasound exposure: implication for drug delivery," Journal of Controlled Release, vol. 104, no. 1, pp. 213-222, 2005.

[9] R. J. Zemp, J. Tavakkoli, and R. S. C. Cobbold, "Modeling of nonlinear ultrasound propagation in tissue from array transducers," Journal of the Acoustical Society of America, vol. 113, no. 1, pp. 139-152, 2003.
[10] S. Ginter, "Numerical simulation of ultrasound-thermotherapy combining nonlinear wave propagation with broadband softtissue absorption," Ultrasonics, vol. 37, no. 10, pp. 693-696, 2000.

[11] J. Tavakkoli, D. Cathignol, and R. Souchon, "Modeling of pulsed finite-amplitude focused sound beams in time domain," Journal of the Acoustical Society of America, vol. 104, no. 4, pp. 20612072, 1998.

[12] H. H. Pennes, "Analysis of tissue and arterial blood temperatures in the resting human forearm," Applied Physiology, vol. 85, no. 1, pp. 5-34, 1998.

[13] W. Shen and J. Zhang, "Modeling and numerical simulation of bioheat transfer and biomechanics in soft tissue," Mathematical and Computer Modelling, vol. 41, no. 11-12, pp. 1251-1265, 2005.

[14] J. W. Durkee and P. P. Antich, "Exact solutions to the multiregion time-dependent bioheat equation with transient heat sources and boundary conditions," Physics in Medicine and Biology, vol. 36, no. 3, pp. 345-368, 1991.

[15] D. Orel and J. Rozman, "A computer simulation of ultrasound thermal bio-effect in embryonic models," Radioengineering, vol. 12, pp. 26-30, 2003.

[16] COMSOL, "User's guide-about comsol multiphysics," Comsol documentation.

[17] M. Pernot, J. Porquet, C. Olive, F. Vignon, D. Cassereau, and J. Aubry, "3D finite differences simulation of coupled acoustic wave and bio-heat equations: skull heating prediction for non invasive hifu therapy," in Proceedings of the World Congress on Ultrasonics, Paris, France, September 2003.

[18] M. Jankun, T. Kelly, A. Zaim et al., "Computer model for cryosurgery of the prostate," Computer Aided Surgery, vol. 4, pp. 193-199, 1999.

[19] A. Trakic, F. Liu, and S. Crozier, "Transient temperature rise in a mouse due to low-frequency regional hyperthermia," Physics in Medicine and Biology, vol. 51, no. 7, pp. 1673-1691, 2006.

[20] P. N. T. Wells, Biomedical Ultrasonic, Academic Press, London, UK, 1977.

[21] W. Hendee and E. Riteno, Medical Imaging Physics, chapter 19, Wiley, New York, NY, USA, 4th edition, 2002.

[22] L. Curiel, F. Chavrier, B. Gignoux, S. Pichardo, S. Chesnais, and J. Y. Chapelon, "Experimental evaluation of lesion prediction modelling in the presence of cavitation bubbles: intended for high-intensity focused ultrasound prostate treatment," Medical and Biological Engineering and Computing, vol. 42, no. 1, pp. 4454, 2004.

[23] R. Souchon, G. Bouchoux, E. Maciejko et al., "Monitoring the formation of thermal lesions with heat-induced echo-strain imaging: a feasibility study," Ultrasound in Medicine and Biology, vol. 31, no. 2, pp. 251-259, 2005.

[24] M. B. Shiran, M. Motevalian, R. Ravanfar, and S. Bohlooli, "The effect of bubble surface charge on phonophoresis: implication in transdermal piroxicam delivery," Iranian Journal of Pharmacology and Therapeutics, vol. 7, no. 1, pp. 15-19, 2008. 


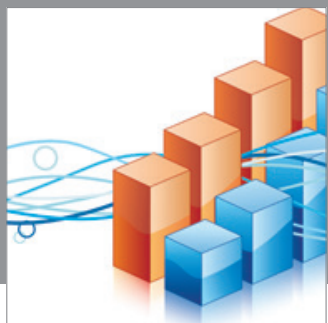

Advances in

Operations Research

mansans

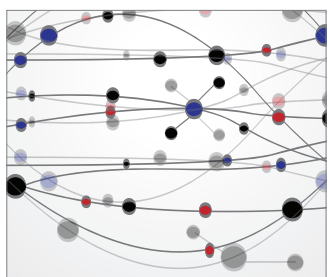

The Scientific World Journal
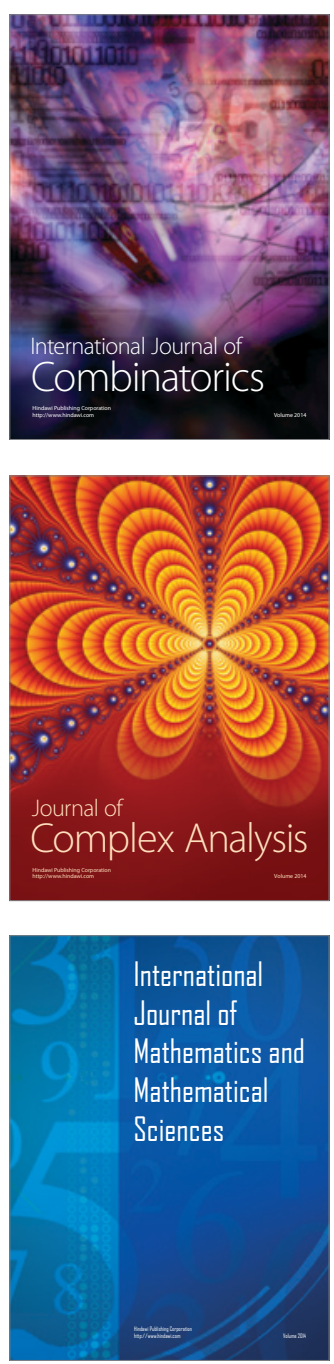
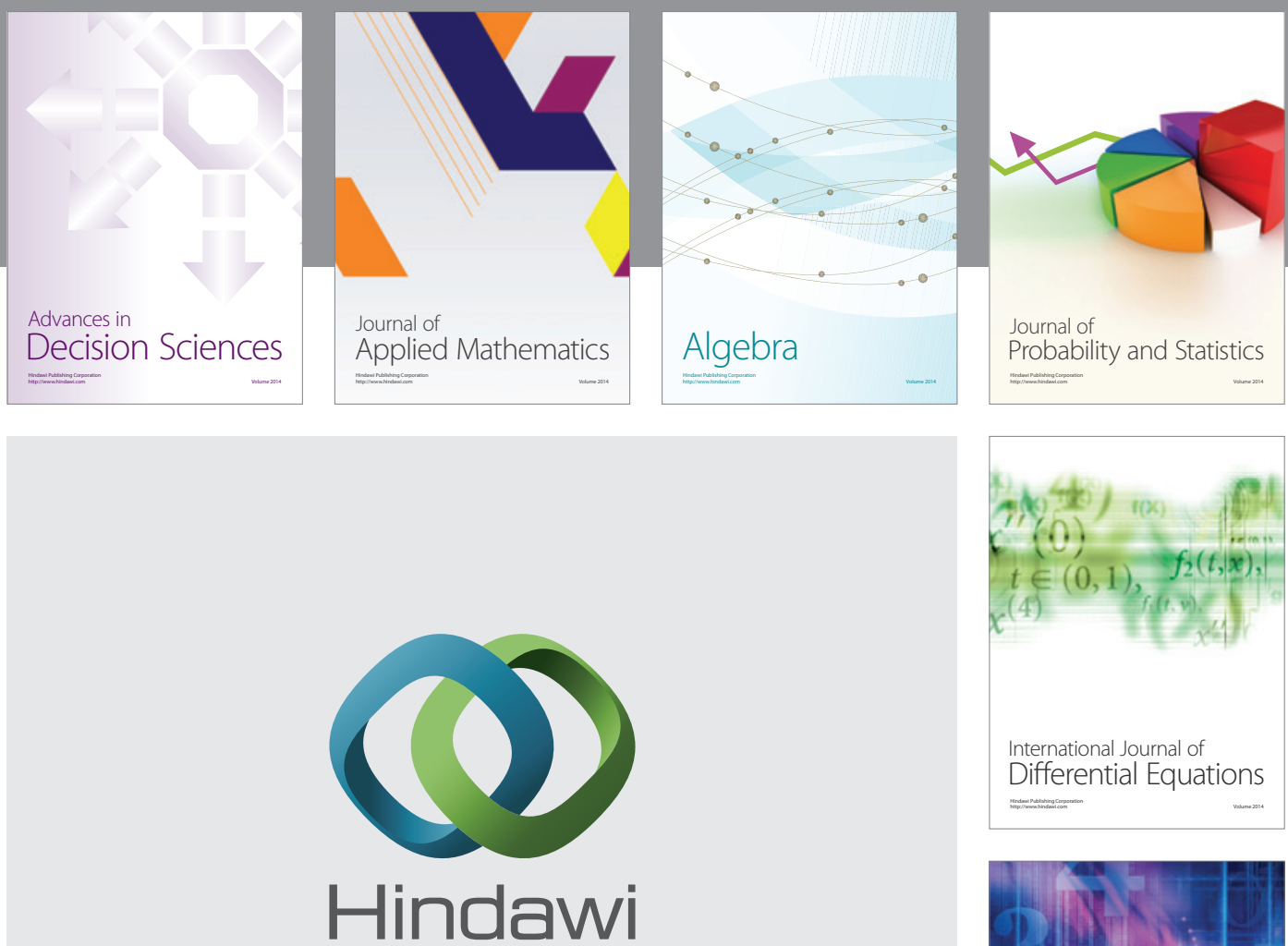

Submit your manuscripts at http://www.hindawi.com
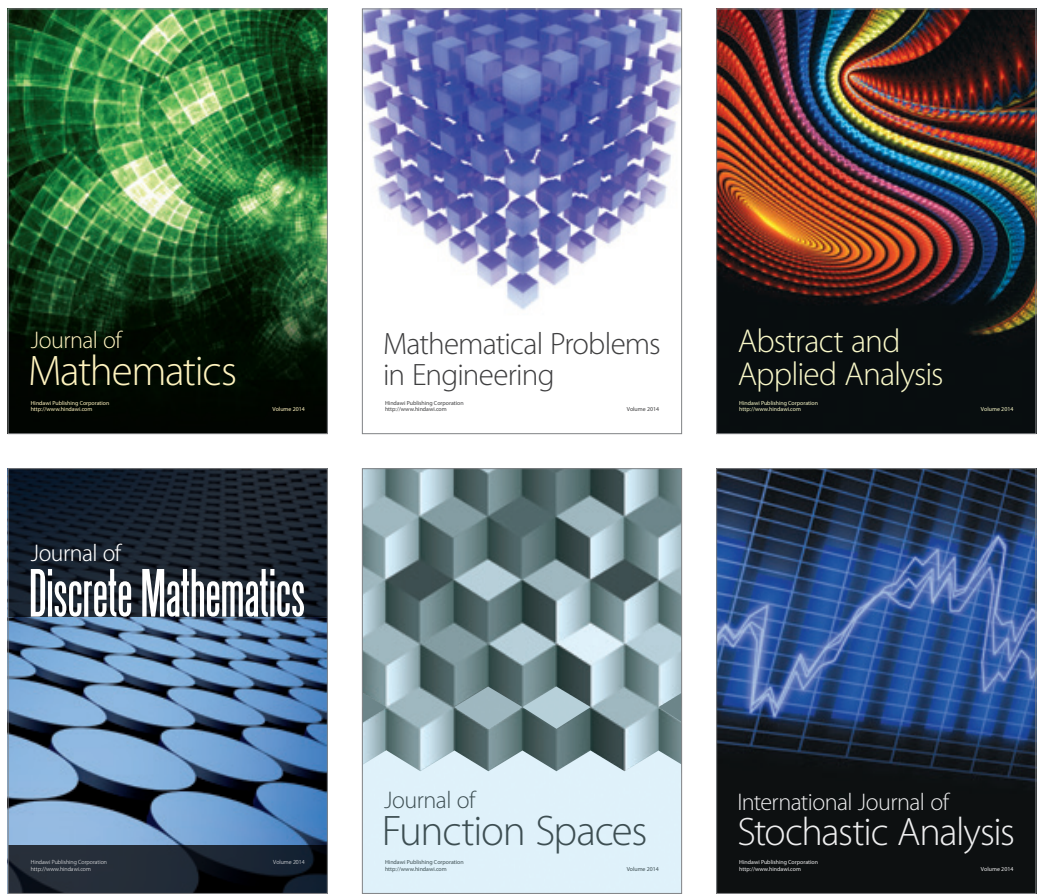

Journal of

Function Spaces

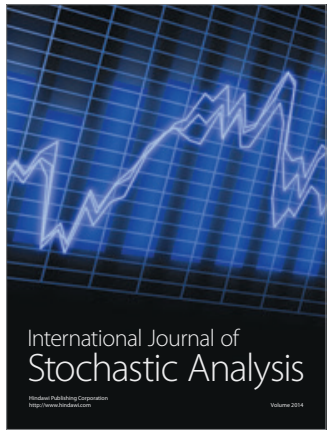

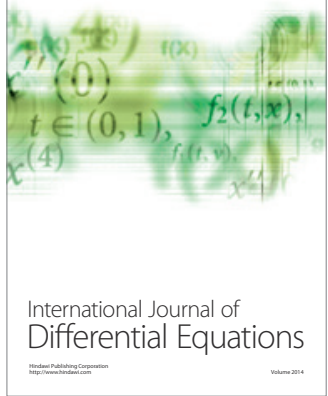
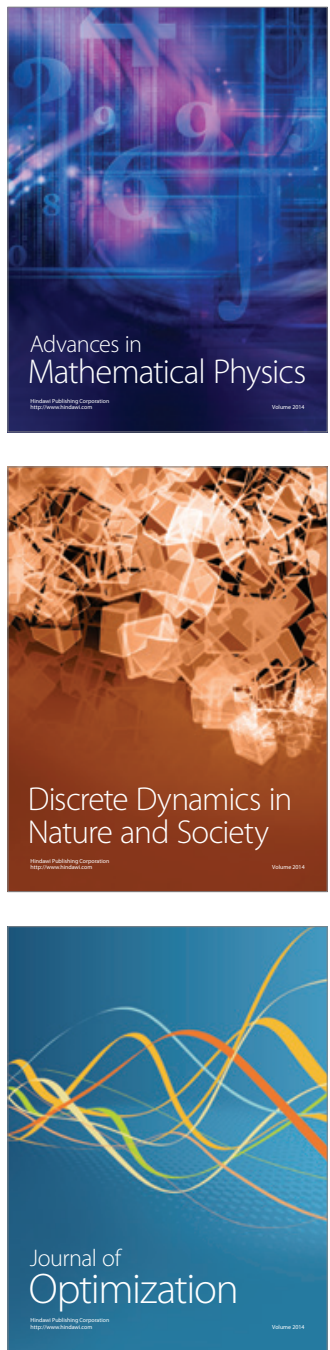